\title{
Voz, visualidade e texto: diálogos poéticos possíveis a partir do trabalho artístico From the forest/ Da floresta de Luana Costa e Hedi Jaansoo
}

Luana Costa ${ }^{1}$

RESUMO: Este trabalho pretende aprofundar as investigações realizadas durante o processo de criação da obra "From the Forest/Da Floresta", trabalho sonoro e visual criado por Luana Costa (Rio de Janeiro) e Hedi Jaansoo (Bergen) durante a disciplina de Pós-Graduação "Voz, Texto, Coletividade", ofertada pela UERJ, ministrada por Ricardo Basbaum no Brasil em parceria com Brandon LaBelle, professor da Academia de BelasArtes da Noruega. O objetivo é prosseguir as análises acerca da produção sonora (oralidades, leituras e suas derivações), intentando alargar as discussões sobre a emissão de voz, e produção de discursos (escrito, gravado), experimentalismos sonoros e fenômenos da linguagem.

PALAVRAS-CHAVE: Voz; discursos; poéticas contemporâneas.

ABSTRACT: This work intends to deepen the investigations carried out during the process of creating the audible and visual work "From the Forest / Da floresta" created by Luana Costa (Rio de Janeiro) and Hedi Jaansoo (Bergen) during the course of Postgraduate: "Voice, Text Collectivity", taught by Ricardo Basbaum in Brazil in partnership with Brandon LaBelle, a professor at the Bergen Academy of Art \& Design, in Norway. The purpose is to continue the analyzes of sound production (orality, readings and their derivations), intending to extend the discussions on the issue of voice and speech production (written, recorded), experimentalism and sonic phenomena of language.

KEYWORDS: Voice; speeches; contemporary poetics.

1 Poetisa, Performer multimídia, Atriz. Professora de Língua Portuguesa e Língua Espanhola. Mestranda em Estudos Contemporâneos das Artes pela Universidade Federal Fluminense - RJ. 


\section{Introdução}

No ano de 2012, os professores e artistas Ricardo Basbaum (UERJ) e Brandon LaBelle (Academia de Belas Artes da Noruega) realizaram através do curso "Voz, Texto e Coletividade/ Voice, Text, Collectivity", uma proposta de criação, experimentação e parceria artística entre os alunos de Pós-Graduação em Artes da Universidade Estadual do Rio de Janeiro e dos alunos de Pós-Graduação da Academia de Belas Artes da Noruega. Naquela ocasião, o curso ofertado pelas duas instituições parceiras buscava problematizar as questões pertinentes às artes sonoras, proporcionando uma investigação acerca da produção e emissão de voz (leitura, fala e seus desdobramentos), dos processos de criação e produção de discurso (escrito, impresso ou gravado), bem como da emissão de voz em domínio coletivo (coros, refrões, manifestações, conversas coletivas e dinâmicas de grupo).

Ao longo do curso o som esteve no centro de nossa pesquisa de tal modo que, buscando iniciar um alargamento de nossas percepções com respeito à arte sonora foram formuladas desde o início do processo de trabalho algumas perguntas concernentes ao campo sônico, tais como: “O que é o ouvir?”; “O que ouvimos?”; "Existem diferentes tipos de escuta?"; "Por que nos concentramos em alguns tipos de sons e ignoramos outros?”. Essas indagações, intermediadas em nossas aulas pelo artista e Prof. Ricardo Basbaum, foram expostas de maneira empírica e delicada, despertando-nos aos sensíveis que essas mesmas questões provocavam - enquanto pensávamos sobre tais perguntas, Basbaum convidava-nos a escutar o som do vento que entrecortava as persianas, o som das buzinas dos automóveis que ressoavam das ruas até a larga janela (um ouvido aberto sobre o mundo) da sala de aula...

Sobremaneira, para pensar um exercício sobre a escuta e ajudar-nos a problematizar questões que foram surgindo-nos, importantes pensadores do som adentraram como escopo de leitura em nossas investigações, dentre eles Christoph Cox

e o texto Beyond Representation and Signification: Toward a Sonic Materialism, Michel de Certau (1996) e sua obra de Vocal Utopias: Glossolalias, o próprio Brandon LaBelle (2006) e a obra Background Noise: Perspectives on Sound Art e o escritor, compositor e educador musical Murray Schafer (1992), autor dentre outras da obra A Sound Education: 100 Exercises in Listening and Soundmaking. 
Tais textos foram discutidos, sempre os associando às experimentações no campo da linguagem e do som realizadas pelos artistas modernos e contemporâneos. A obra de Schafer no entanto revelou-se de destacada importância para nossos apontamentos pois através dos exercícios sonoros propostos pelo autor logramos discutir alguns pontos chave pertencentes ao campo sônico nos fazendo valer de muitas das assertivas do autor sobre as experimentações sonoras.

Destaquemos algumas observações de Schafer contidas em A Sound Education. Nesse seu trabalho o pesquisador canadense afirma que o ambiente ao nosso redor seria uma potente paisagem sonora, e a escuta não seria uniforme, tampouco a mesma para todos os indivíduos - não apenas os indivíduos escutariam de formas diferentes entre si como também as sociedades e culturas possuiriam escutas distintas umas das outras, já que a paisagem sonora do mundo seria "incrivelmente variável diferindo de acordo com a hora, a estação, o lugar e a cultura" (SCHAFER, 1992, p. 8, tradução minha). Haveriam ainda diferenças entre o que ele chamou de "escuta concentrada" e "escuta periférica", escutas pela quais determinados sons se sobreporiam culturalmente sobre outros, deixando à margem certos sons ignorados em sua matéria sonora. Para ilustrar essa afirmação destaco aqui algumas das indagações propostas pelo autor:

Por que nós nos concentramos em determinados sons, enquanto que outros ouvimos apenas por acaso? Seriam alguns sons descriminados culturalmente de modo a não serem ouvidos de nenhum modo? (Um africano disse certa vez: 'O Apartheid é um som!'). Alguns sons são filtrados ou tornados imperceptíveis por outras pessoas? E como é que a mudança do ambiente acústico afetaria os tipos de sons que escolhemos para ouvir ou ignorar? (SCHAFER, 1992, p. 7-8, tradução minha).

Ao revelar o campo sonoro como uma paisagem passível de ser delimitada, edificada, com sons culturalmente aceitos e outros ignorados, o autor expõe em seguida que uma consciência sobre o som e os diferentes modos de ouvir devem ser por nós repensados de maneira profunda, amplificada. Para ele muitos dos sons que escutamos na contemporaneidade são apenas frutos de produções de nossa civilização mecanizada, que desde o século XX teria nos sobrecarregado sensorialmente com sua floresta de engenhocas ruidosas. A produção musical a partir do século $\mathrm{XX}$ teria sofrido uma transformação drástica em suas práticas por meio de tecnologias que teriam modificado 
as técnicas da escuta e manipulação gerando conseqüências devastadoras para com as práticas musicais e a maneira de ouvir configuradas até então. Afirma o autor que desde tais consequências, os sons que ouviríamos seriam culturalmente impostos, delineando uma paisagem sonora poluída e desesperadora que nos afetaria psicologicamente de modo negativo e ensurdecedor, tornando nossos sentidos deveras submisso, silenciado, não-criativo. No entanto, seria possível mudar essas configurações sonoras impostas socialmente através do desejo de uma escuta sensibilizada. Tal escuta seria produto de uma atuação consciente e participante sobre nosso mundo sonoro e se daria através de exercícios práticos e do retorno de hábitos já não mais incorporados ao nosso cotidiano.

Um importante hábito destacado pelo autor ao longo de sua obra seria o de aprender a ouvir. Este hábito seria uma necessidade fundante para um efetivo processo de sensibilidade e educação sonora afim de transformarmos nosso modo de ouvir e a paisagem sonora ruidosa em que vivemos. Sobre essa reaprendizagem da escuta, assim afirmou o autor:

\begin{abstract}
Eu acredito que o caminho para melhorar a sonoridade do mundo é bastante simples. Devemos aprender a ouvir. Parece ser um hábito que nos esquecemos. Devemos sensibilizar o ouvido para o mundo milagroso de sons que nos rodeiam. Depois de ter desenvolvido alguma perspicácia crítica, podemos ir para projetos maiores, com implicação social, de modo que outras pessoas podem ser influenciadas por nossas experiências. O objetivo final seria começar a tomar decisões conscientes sobre projetos que afetam a nossa paisagem sonora (SCHAFER, 1992, p. 11, tradução minha).
\end{abstract}

Aprender a ouvir e exercitar a própria escuta para verter nosso ouvido autômato em um ouvido pensante, eis o propósito do autor. Abrir as terminações nervosas dos ouvidos dos outros sentidos - esgarçar a escuta do paladar, a escuta do tato, dos poros, do olhar. Tornar visível a todos os sentidos o invisível, decidir conscientemente e de maneira crítica a nossa experiência sonora incorporando-a de fato às nossas vidas. Tarefa aparentemente árdua, porém simples quando intermediada pelo desejo, o simples desejo de ouvir... E foi mesmo de modo a refletir a escuta enquanto pulsação poética desejante, enquanto experimentação, enquanto sensação, possibilidade e um modo de estar e agir no mundo, que trabalhamos os elementos sonoros de modo singular e coletivo durante o curso "Voz, Texto, Coletividade". 
Tendo o pensamento sobre o campo sonoro conjugado à ação e como modo efetivo de interferir conscientemente em nossa paisagem sonora, fomos estimulados pelos professores Ricardo Basbaum no Rio de Janeiro e Brandon LaBelle na Noruega, para realizar um trabalho artístico que valorizasse a experimentação sonora e se fizesse valer de recursos técnicos durante sua elaboração, tais como o gravador sonoro para a captação do som de modo a abarcar as questões suscitadas ao longo do curso pensando e experimentando o sonoro no contemporâneo.

Acerca da possibilidade de captação dos eventos sonoros, esta é fruto das transformações causadas na prática musical desde o século XX que, como nos revela o pesquisador e compositor de música experimental Michel Chion (1994) autor de Música, media e tecnologia a forma de se produzir o som teria se alterado drasticamente a partir das novas tecnologias insurgentes. Tais tecnologias permitiram alterar os modos de produção do som pois através delas qualquer som poderia ser agora capturado e posteriormente reproduzido, gerando por sua vez uma cisão entre a fonte sonora e seu resultado sonoro. Tal mudança tornou desnecessário que durante a escuta de um som sua fonte estivesse presente; seria preciso somente do suporte de registro do som captado. E foi assim, através de um trabalho inicial pela captura de sons, que nossa experiência sinestésica teve início.

A captação de eventos acústicos de diferentes paisagens sonoras e a partilha coletiva dos sons coletados deu-se como um profícuo exercício experimental ao longo do curso. Demos início às nossas conversas sobre a voz, o texto e a coletividade em processos artísticos sonoros estimulado pelas propostas de Schafer (1992); referenciando-nos em artistas sonoros da vanguarda - tais como John Cage (1912-1992), Alvin Lucier (1913) e Karlheinz Stockhausen (1928-2007); bem como em artistas contemporâneos como o próprio Ricardo Basbaum e seu trabalho sonoro "conversas coletivas".

Sobre essas conversas coletivas do autor, elas se constituíram de ações performáticas pertencentes ao trabalho "conversas \& exercícios [área instalação + conversa coletiva]" exposto na $30^{\mathrm{a}}$ Bienal de São Paulo no ano de 2012 e trataram-se de leituras públicas desenvolvidas em Workshop e realizadas com participantes e convidados (dentre eles Brandon LaBelle) na área de instalação do trabalho do autor no espaço da Bienal. Visando integrar o texto escrito à sua emissão sonora de forma a incorporar os discursos diversos que irrompem na arte contemporânea, a conversa coletiva 1 "fala, som, texto" e a conversa coletiva 2 "grupo, coletivo, experiência" 
deram-se em grupo e de forma multivocal, polifônica. Criado o trabalho a partir do Workshop, uma leitura pública coletiva foi realizada na Bienal. Naquela ocasião alguns alunos do curso "Voz, Texto, Coletividade" também participaram do workshop estando presentes na leitura pública do trabalho.

A partilha das experiências sonoras dos trabalhos artísticos de Ricardo Basbaum foram importantes para ajudar-nos a seguir em nossas elucubrações sobre os elementos sonoros do próprio curso. Ainda que a captação sonora de ruídos tenha sido realizada por cada um de nós, interessava também abarcar experimentações relacionadas à voz e ao texto, pensando-o em sua possível multiplicidade sonora, coletiva. Ao longo do curso partilhamos com o grupo algumas experiências sonoras individuais, discutindo-as. Cada aluno revelava ao longo da partilha certas inclinações acústicas.

Como poetisa, interessou-me as possibilidades e intervenções sonoras sobre o texto e através da poesia falada, de forma a criar uma espécie de poética da voz. A fala poética como evocação da arte performática que integra palavra, o corpo, e a voz é um campo que venho experimentando desde 2003. Em Cuiabá-MT, realizei minhas primeiras experimentações de poesia falada no Encontro dos Poetas Livres ${ }^{2}$ nas Praças Cuiabanas e dei início também aos meus trabalhos poéticos e performáticos em diálogo tcom as artes visuais, tendo a fotografia como suporte.

Imbricada à performance, os desdobramentos das experimentações poéticas que atualmente tenho realizado em parceria com o ator, músico e fotógrafo Jone Castilho é trabalhada sempre no intuito de expandir o texto para outras esferas como a voz, o corpo e as artes visuais, como se pode ver em uma de nossas experiências fotográficas que se segue:

2 O Encontro dos Poetas Livres nas Praças Cuiabanas foi idealizado em 2001 pelo poeta cuiabano Neneto Sá e obteve ao longo de sua existência a presença de muitos poetas de Cuiabá, que temporária e nomadicamente habitavam as praças da cidade para falar e ouvir poesia. 


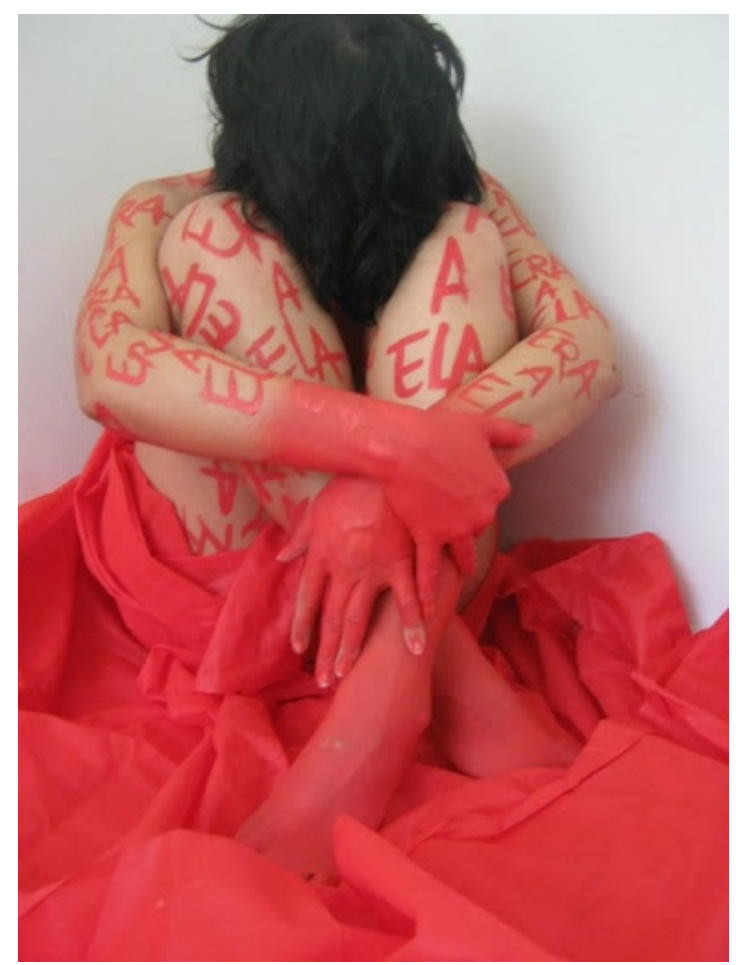

Fig. 1. Era a Ela. Fotografia: Jone Castilho. Corpo: Luana Costa.

Pintura corporal: José Cardoso, julho de 2011. Exposta na mostra 1 Instante, Niterói. 
O desejo de criar diálogos entre o texto e as poéticas visuais como pode-se perceber também sempre acompanhou-me em minhas inquietações artísticas. E não foi diferente quando da proposta de realização de uma obra artística sonora por parte dos professores e artistas Ricardo Basbaum e Brandon LaBelle durante curso "Voz, Texto, Coletividade" no ano de 2012. Para a realização do trabalho correspondente a este curso de artes sonoras tive de empreender uma experimentação profunda do campo textual enquanto potencialidade sônica. Esgarçar o som enquanto elemento de plasticidade acústica por meio de tecnologias contemporâneas tal como gravadores sonoros e programas para gravação e audição de áudio foram eventos inéditos para mim. Sobremaneira, este trabalho não concretizou-se de modo individual. A intenção dos professores foi a de efetuar uma parceria entre os estudantes de Pós-Graduação em Artes do Rio de Janeiro e os estudantes de Pós-Graduação da Academia de Belas Artes da Noruega. Selecionadas por afinidade curricular pelos professores - Ricardo Basbaum no Rio de Janeiro e Brandon LaBelle na Noruega - o meu trabalho no curso deu-se em parceria com a artista estoniana Hedi Jaansoo. Os processos de nosso trabalho rumo à criação de nossa obra tiveram início em outubro de 2012, quando do primeiro contato por correio eletrônico, como se detalhará.

\section{Primeiros diálogos: Sonoridade, visualidade e texto no processo de criação da obra From the Forest/Da Floresta}

Hedi Jaansoo enviou-me àquela data um arquivo de sua voz e uma imagem da floresta da Estônia (Fig.2), país báltico da Europa Setentrional e seu país natal. No texto enviado junto à imagem ela detalhava-me o interesse em fazer desta imagem um elemento para nossa obra em processo. 


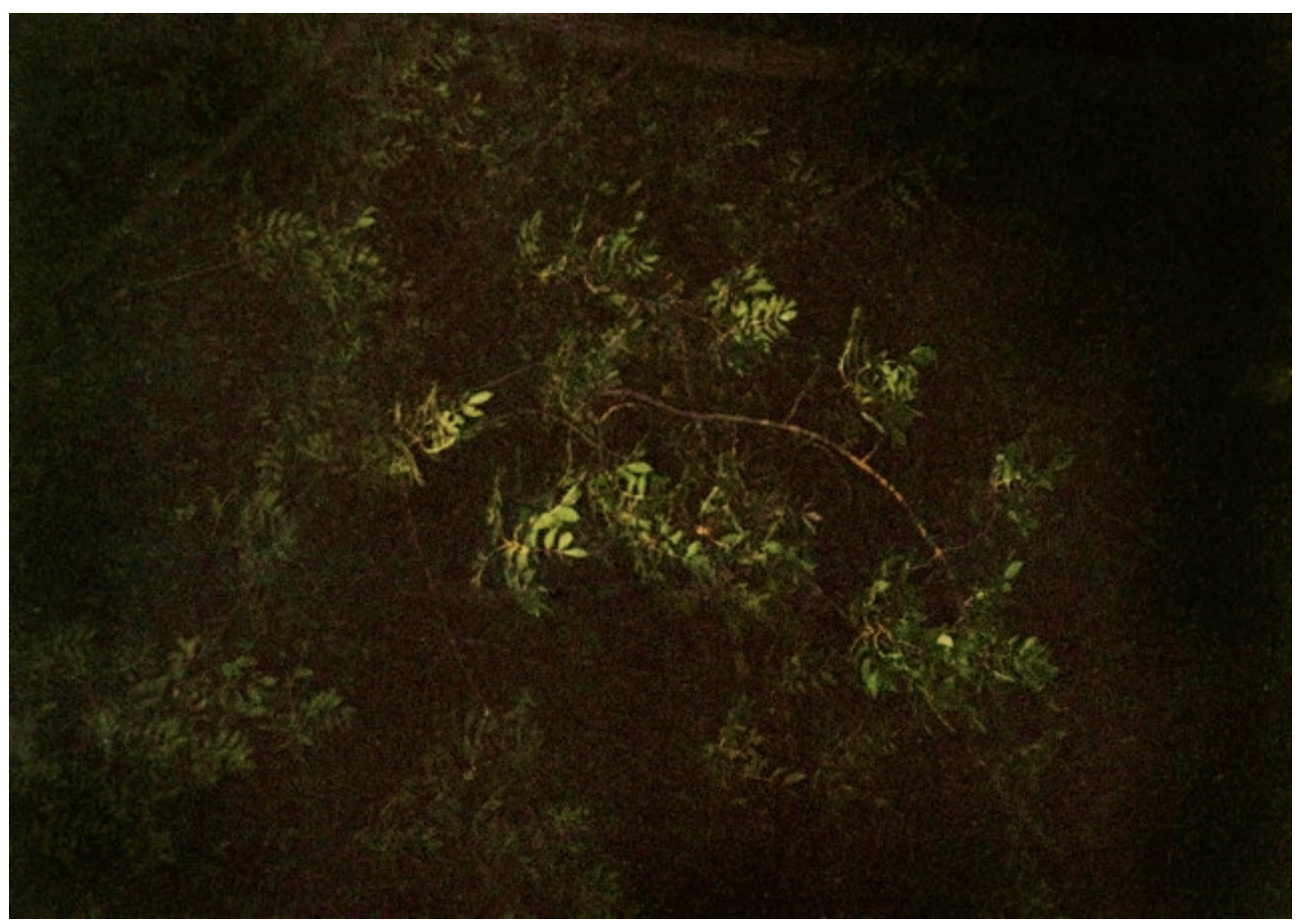

Fig.2 Floresta da Estonia. Hedi Jaansoo, 2012

Segundo havia-me me afirmado Jaansoo, o seu desejo era o de editá-la em movimento circular, movimento este que para ela simbolizava o ritmo e a continuidade da vida. A artista desejava também associá-la ao som de sua respiração para acentuar a proposta da relação intrínseca entre a natureza e a vida humana. 
Paralelamente ao envio da imagem da floresta por Hedi Jaansoo, eu efetuava uma visita para Rio Branco, capital do Estado do Acre. Tal viagem, aproximando-me da Floresta Amazônica, despertou meu interesse pela flora brasileira e os elementos da natureza enquanto material e matéria potente para a criação artística.

Já completamente envolvida e contaminada pelas elucubrações do curso e as assertivas sobre as paisagens sonoras, dei início aos meus primeiros registros dos eventos sonoros daquela região. A intenção da viagem havia então se convertido também no desejo de executar captações de sons através do gravador sonoro, companheiro inseparável desde o início do curso; apontar impressões escritas e fotografar a cidade de Rio Branco ainda desconhecida aos meus olhos e ouvidos era também o meu intuito.

Tendo em mãos desde o início da viagem um caderno confeccionado por mim e intitulado "Caderno de Sonhos", realizei em suas folhas em branco a anotação diária de meus sonhos na capital do Acre e a escrita de impressões do lugar durante minhas caminhadas pelo local.

Como um exercício de escuta para o fazer sonoro realizei um primeiro vídeo da imagem de uma forte chuva que caíra em Rio Branco dando ênfase ao seu som; gravei os ruídos de coachares de sapos em diversos pontos da Universidade Federal do Acre; da voz de um indígena fazendo um pronunciamento público nessa mesma Universidade; escrevi da sensação experimentada quando de meu alojamento na moradia indígena existente na Universidade Federal do Acre; descrevi em meu caderno os sabores da comida oferecida a mim e feitas por um casal de indígenas que ali estavam; detalhei sobre a noite em que todos que cantávamos e contávamos histórias ao redor de uma fogueira durante uma noite calorosa sob a Lua crescente. A expectativa era a de fazer destes escritos um dado para agregar aos processos artísticos de nossa obra quando de meu retorno ao Rio de Janeiro.

No entanto, tais expectativas viram-se momentaneamente perdidas quando do extravio deste caderno no Aeroporto de Belo Horizonte - Minas Gerais. Ao retornar à minha morada no Estado do Rio de Janeiro, desejei salvaguardar de algum modo as impressões e sensações que ainda estavam vivas em minha memória.

No anseio por capturar essas impressões um tanto fantasmáticas desta ida à capital do Acre em parte esquecidas como alguns de meus sonhos anotados periodicamente durante os quatro dias que lá passei, tomei a decisão de realizar uma escrita literária desta viagem. Tal escrita poderia de algum modo condensar a 
experiência e ser uma espécie de cartografia mnemônica poética de minha vivência no local. Escrevi então um texto e dediquei-o ao Acre. Intitulei-o Sonho Amazônico. Eis os seus versos:

\section{Sonho Amazônico}

No seio da Floresta

Vi pajés coloridos entoarem cânticos

Índias de prata abrirem estrelas

E entregar suas luzes como oferenda

Para fazer dançar

os príncipes-trovões

No seio da Floresta

Vi o Sol transformar

os pássaros em ouro

Vi raízes e folhas virarem manto

E o leite das árvores dos seringais

Pintarem de branco

os cabelos dos Rios

No seio da Floresta

Vi o Povo da Água emergindo da chuva

Vi o Povo do Fogo sobre os raios do Sol

Vi o Povo da Terra saindo das grutas

E mulheres guerreiras voltando das lutas

No seio da Floresta

Ouvi as vozes das sereias-feiticeiras

Onças aladas movendo-se nas telhas

Ouvi pulsar o coração de uma estrela 
No seio da Floresta

Com meu terceiro olho sônico

Movi-me nas densas trilhas de éter

Rumo a um íngreme sonho amazônico.

Após escrevê-lo apresentei o texto escrito em língua inglesa à Hedi Jaansoo, que respondeu-me com entusiasmo e enfatizando a aproximação de eventos de sua própria vida com os versos da terceira estrofe do poema. A partir desta escrita e da recepção positiva pela artista sugeri que realizássemos uma conjugação da experiência sonora da terceira estrofe deste texto com sua imagem da Floresta da Estônia, mas de modo a operar de modo distinto e não convencional com a emissão sonora de minha voz. Aqui destaco a importância da leitura do texto de Michel de Certau (1996) durante o curso para o pensamento deste procedimento sônico.

Afeta-me os fenômenos de linguagem que apontam para os desejos e atos de transcriação das operações normativas da língua e as manifestações linguísticas que indicam uma elaboração de alteridades para a criação de um tópos literário capaz de causar uma fissura na própria verve da linguagem - fenômenos e ações poéticas das quais o escritor Ghérasim Luca ${ }^{3}$ (1913-1994) constitui uma importante referência para mim. Ora, sobre tais fenômenos, em especial a glossolalia, Michel de Certau, assim afirmou sobre suas emissões:

Arte da fala [un art de dire] dentro dos limites de uma ilusão (...) desregulam a organização dos sistemas de significado como ervas daninhas que crescem por entre o concreto. Por um momento, como o ritual 'Loa' Vodu, as vozes se apossam do discurso. (CERTAU, 1996, p. 29, tradução minha).

No caminho de uma intervenção sonora menos à ordem dos ditames orais e mais à desconstrução dos discursos majoritários da linguagem, procurei realizar uma gravação sonora da poesia que fosse convidativa para a entrada nessas perturbações linguísticas e

3 Segundo Guilherme Castelo Branco, para o poeta romeno Ghérasim Luca, a poesia seria "uma operação pela qual cada palavra é submetida a uma série de mutações sonoras, e cada uma das facetas da palavra acaba por libertar a multiplicidade de sentidos que ela carrega, algumas delas radicalmente novas" (CASTELO BRANCO, 2010, p. 81). 
incitasse ao segredo e ao secreto, ao ritual e ao mágico, já que minha experiência vivida na região Amazônica também havia sido atravessada pelo ritualístico.

Assim, a gravação sonora da $3^{a}$ estrofe foi realizada de modo que a impostação de minha voz fosse outra que não a minha natural e usual nos modos de fala convencionais. Falada de maneira sussurrante, emiti-a como se tais palavras fossem próprias de um segredo contado aos ouvidos de alguém por alguma entidade ou espírito das florestas.

$\mathrm{Na}$ intenção de também preservar a ideia sugerida por Hedi (imbricar a imagem em loop da floresta da Estonia ao som de sua respiração) e seguindo a sugestão dada em sala de aula pelo Prof. Ricardo Basbaum, reeditei o som de minha voz sussurrada ao som de minha respiração sobrepondo-as. Minha respiração, feita de modo convulsivo, anti-natural e bastante marcado através de minha inspiração efetuada pela boca possibilitou converter o trabalho sonoro em uma dupla voz, um duplo som, uma voz coletiva.

Traduzida para o inglês, a gravação foi novamente enviada para Hedi Jaansoo, que realizou a edição final junto ao seu vídeo da floresta estoniana de maneira que o som acabou por torna-se uma emissão sônica em loop e em uníssono com a imagem da floresta. Estes processos desaguaram por fim em nossa obra From the Forest/Da floresta, constituindo assim um encontro singular entre nossas florestas, intermediadas pelos diálogos entre texto, voz e imagem.

O nosso trabalho artístico integrou a exposição Dupla-Boca/Double-Mouth sob curadoria dos professores e artistas Ricardo Basbaum e Brandon LaBelle tendo sido levada à público, junto aos demais trabalhos de outras duplas de alunos, na exposição realizada em Bergen, Noruega e na Galeria Cândido Portinari da Universidade Estadual do Rio de Janeiro, Brasil. 


\section{Referências bibliográficas:}

CERTAU, Michel. Vocal Utopias: Glossolalias. In: Representations, Volume o, Issue 56, Special Issue: The new Eruditon. Automn, 1996.

COX, Cristoph. Beyond Representation and Signification: Toward a Sonic Materialism. In: Journal of Visual Culture, vol. 10. Sage Publications: Los Angeles, London, New Delhi, Singapore and Washington DC, August, 2011. Disponível em: http://vcu.sagepub.com

CHION, M. Música, media e tecnologia. Lisboa: Instituto Piaget, 1994.

Foucault, M. 2006. "Outros Espaços". Estética: literatura e pintura, música e cinema, Ditos e Escritos Vol. III, Rio de Janeiro, Forense Universitária.

SCHAFER, R. Murray. A Sound Education. Canada: Arcana Editions, 1992.

LA BELLE, Brandon. Background Noise: Perspectives on sound art. Continuum International Publishing Group: New York, 2006.

VASCONCELOS, Jorge; BRANCO, Guilherme Castelo. "Michel Foucault e a Literatura" In: Arte, vida e política: ensaios sobre Foucault e Deleuze. Rio de Janeiro: LCV, 2010. 